\title{
Towards Sustainable Construction Practices: How to Reinvigorate Vernacular Buildings in the Digital Era?
}

\author{
Christina Priavolou ${ }^{1,2, *(D)}$, Nikiforos Tsiouris ${ }^{1}$, Vasilis Niaros ${ }^{2,3}$ and Vasilis Kostakis ${ }^{1,2}$ \\ 1 Ragnar Nurkse Department of Innovation and Governance, Tallinn University of Technology (TalTech), \\ Akadeemia tee 3, 12618 Tallinn, Estonia; nikiforos.tsiouris@taltech.ee (N.T.); vasileios.kostakis@taltech.ee (V.K.) \\ 2 P2P Lab, Papadopoulou 5B, 45444 Ioannina, Greece; vniaros@uoc.edu \\ 3 Internet Interdisciplinary Institute, Universitat Oberta de Catalunya, Rambla del Poblenou, 156, \\ 08018 Barcelona, Spain \\ * Correspondence: christina.priavolou@taltech.ee
}

check for updates

Citation: Priavolou, C.; Tsiouris, N.; Niaros, V.; Kostakis, V. Towards Sustainable Construction Practices: How to Reinvigorate Vernacular Buildings in the Digital Era? Buildings 2021, 11, 297. https://doi.org/ 10.3390/buildings11070297

Academic Editor: Wahidul Biswas

Received: 14 May 2021

Accepted: 4 July 2021

Published: 7 July 2021

Publisher's Note: MDPI stays neutral with regard to jurisdictional claims in published maps and institutional affiliations.

Copyright: (c) 2021 by the authors. Licensee MDPI, Basel, Switzerland. This article is an open access article distributed under the terms and conditions of the Creative Commons Attribution (CC BY) license (https:// creativecommons.org/licenses/by/ $4.0 /)$.

\begin{abstract}
The starting point of this article is the critique on socioeconomic and environmental implications of conventional construction practices around sustainability. The focus is on exploring the sustainability dynamics of the emerging "Design Global, Manufacture Local" (DGML) configuration with emphasis on building construction. Combined with the concept of conviviality which we identify in aspects of vernacular architecture we explore how it can foster meaningful sustainability practices in the construction sector. We introduce a framework of "open construction systems", an expression of DGML in building construction, as a way to foster the conjunctive use of the digital commons and local manufacturing technologies for the construction of buildings through three interlocked elements-modularity, sharing and adaptability. We suggest that the "open construction systems" framework may point towards more sustainability in building construction.
\end{abstract}

Keywords: construction; building; commons; sustainability; conviviality

\section{Introduction}

There is a wide range of sustainability conceptualisations in the literature. The concept of sustainability was first introduced to indicate a harvesting practice that can be maintained for generations, considering the natural regeneration of forests [1]. It was subsequently used to raise environmental awareness at a global level [2]. Today a mixture of environmental, social, and economic elements exists in the concept of sustainability known as the three pillars of sustainability [3].

In the construction sector, sustainable practices present common values, such as the focus on resource efficiency, social cohesion, and the adoption of cost-effective methods that meet human needs [4]. However, there is no regulatory framework that explicitly states the roles and responsibilities of various stakeholders and clearly describes the process to be followed for a sustainable transition in construction. It has been argued though that sustainability in building construction could thrive through collaborative efforts by the involved stakeholders across the stages of construction [5].

In this article, we posit that conviviality could provide the necessary tools for enhanced sustainability practices in the construction sector. Conviviality is an ethical value that relies on human coexistence and interdependence for wellbeing [6]. In contrast with a convivial approach, the pursuit of growth-oriented approaches "defuturises" the future, meaning that the future is deprived of part of its potential $[7,8]$. In addition, these approaches may negatively impact people, causing mental health issues or undermining morality $[9,10]$.

We identify a strong presence of conviviality in vernacular buildings. Vernacular architecture refers to a modest style of building that relies on the use of local resources and knowledge to construct buildings. Vernacular buildings constitute exemplifications of how 
conviviality can be deployed in the construction sector and provide multiple benefits to the three pillars of sustainability.

Furthermore, we draw inspiration from an emerging production configuration based on the digital commons, which is codified as Design Global, Manufacture Local (DGML) [11]. Building on DGML in conjunction with the conviviality present in vernacular architecture, we introduce Open Construction Systems (OCSs), which expand the focus of attention from the building structure to the ecosystem around it, required to enable the lifecycle management of buildings. The questions that have acted as a trigger for this article are: How could vernacular buildings evolve in tandem with current technological regimes to provide local responses to the global pressing need for sustainability in building construction? Could OCSs provide a solution towards that direction?

Looking towards fostering sustainability, we argue that OCSs could inaugurate a conviviality-inspired sustainable pathway in building construction by reinvigorating vernacular architecture and reinforcing it with technological capacities [7,12]. In other words, it borrows elements from both contemporary digital tools used in the construction and the tacit knowledge found in vernacular practices still employed in developing regions of the planet. We hence elaborate on three interlocked elements for conviviality observed in the development of OCSs using the Matrix of Convivial Technology [13]. We also discuss the potential benefits these elements could have on the construction sector.

The remaining part of this article is organised as follows. Section 2 discusses sustainabilityrelated issues in the construction sector, introduces the DGML configuration and indicates how conviviality could boost sustainability practices in buildings as exemplified through vernacular architecture. Section 3 describes the framework of OCSs, elaborating on how core elements of OCSs could enhance conviviality in building construction and we discuss the positive impact this may have towards sustainability. Finally, Section 4 summarises our insights.

\section{Shifting towards Sustainability in Building Construction}

\subsection{Sustainability in Conventional Construction Practices}

In the context of the conventional construction practices, a producer-consumer relationship has been established that restricts the engagement of individuals in the construction process, infringing on the human right to housing $[14,15]$. Further, high rates of gender discrimination, corruption, and labour-intensive activities have been observed in building construction, while the quality performance of buildings is usually disregarded in pursuit of maximising economic gains [16]. In addition, detrimental environmental effects of the construction sector cannot be overlooked, considering that building construction accounts for $39 \%$ of global carbon emissions [17,18].

Despite the identification of these issues, construction practices have barely changed during the last six decades [19-21]. The need to implement sustainable practices in building construction has only recently attracted attention [22]. Although there is not yet a unified framework for sustainable construction, it has been strongly posited that multidimensional and collaborative approaches should be implemented to achieve a shared vision on sustainable construction [5]. Towards that goal we believe that the elements of OCSs enabled through the DGML configuration could play a key role in addressing several of the aforementioned issues.

\subsection{Introducing the Design Global, Manufacture Local Configuration}

Information and Communication Technologies (ICTs) have facilitated the development of digital platforms that favour online information sharing. Given the potential of these platforms to enhance collaboration and knowledge transfer at low costs, ICTs have been portrayed as a booster of democratisation [23,24]. Immaterial resources (such as knowledge, software, and designs) can be distributed through the Internet and shared around the globe as a "digital commons" [25] "Digital commons" can be utilised to provide local solutions, bearing in mind surrounding biophysical conditions [11]. 
At the same time, local manufacturing technologies (i.e., 3D printers and laser cutters) enable the production of objects locally, thus facilitating distributed production networks with significant societal impacts [26]. The distribution of these technologies boosts creativity and experimentation, offering opportunities for transitions towards sustainability and peer-to-peer ways of producing artefacts [27]. The development of open source hardware solutions (for example the Arduino microcontroller board (https: //www.arduino.cc/en/guide/introduction. Accessed on 6 July 2021) and Open Bionic Systems (https: / / openbionics.org/. Accessed on 6 July 2021) exemplifies how the manufacturing process of physical products can be transformed through collaborative efforts [11].

The convergence of global "digital commons" with local manufacturing technologies has been outlined through the DGML configuration. DGML differs from the conventional market-driven production one in its promotion of distributed production realised in local but networked makerspaces $[11,28]$. The collective intelligence and cooperation embedded in the development of DGML solutions strengthen the potential of relevant initiatives to foster innovation [29]. Information behind the development process of technological solutions is shared as a "digital commons", which can undergo asynchronous modifications by contributors.

DGML communities produce technological solutions locally on-demand through sharing both digital and physical infrastructure. Further, they purposely design products to last, focusing on social wellbeing while moving away from profit maximisation-oriented practices [30]. The primary motives of commons-based communities stem from their need for communication, learning, and emotional fulfilment [23], aligning with values like sociability and self-development embedded in convivial processes. Besides, research has illustrated interrelated practices observed in the development of DGML products that create positive feedback loops towards conviviality [11]. Thus, it can be posited that DGML practices could foster the human-centric shaping of technology.

\subsection{A Conviviality-Based Sustainability}

Echoing [6], conviviality is an intrinsic ethical value that correlates with "individual freedom realised in personal interdependence". "Survival, justice and self-defined work" are basic ideals of conviviality [6] that summarise key values included in the concept of sustainable development [31]. The social pillar of sustainability is associated with human wellbeing and includes a large list of issues related to education, social inclusion, health, safety, housing, employment and more [32]. In a convivial setting, the broader public is involved in the decision-making and production processes. Hence, human needs are taken into account, while perceptions around wellbeing can be redefined and configured collectively [7].

Pursuing a path to conviviality is not easy. There is a need to transform existing production and consumption models, as advocated by the degrowth movement [33]. The idea is to prioritise the assimilation of conviviality ideals in daily life instead of merely enhancing efficiency and optimising performance to achieve sustainability [34]. Besides, the use of energy-efficient systems does not necessarily mean that less consumption takes place if consumption patterns remain unchanged [35].

Convivial technologies are designed in such a way that users can learn about the technology and modify it according to their needs, without the necessity of relying on specialists [36]. They are decentralised, reversible, and democratically controllable [37]. Decentralisation takes place through the implementation of small-scale production units that create distributed supply chains by using local resources [28]. Reversibility is enhanced when the "black-box" behind the development process of products opens up to the public, enabling the transparency of information and inclusion of users in the production of artefacts [38]. By keeping technologies under democratic control, groups of individuals can produce technologies in a collaborative manner to cover their own needs [6].

Conviviality is a broad and abstract concept. In order to provide an accessible and comprehensive means of assessing the degree of creativity, autonomy, and decentralisa- 
tion in community-based practices, the Matrix of Convivial Technology (MCT) has been developed [13]. As an empirical tool, the MCT allows participants in technological development processes to examine certain conviviality elements on a case-by-case basis (see Appendix A). As depicted in Figure 1, different levels connected to the impact of technology on human relations (relatedness), the adaptability of technology to local contexts, accessibility to technological means, the bio-interaction of technology with the environment, and the appropriateness of socio-ecological benefits of technology in relation to its socioecological impact are examined.

\begin{tabular}{|c|c|c|c|c|}
\hline Levels & Materials & Production & Use & Infrastructure \\
\hline Relatedness & $\begin{array}{l}\text { Organization distributed } \\
\text { Need-driven } \\
\text { Bottom-up control } \\
\text { Local traditions }\end{array}$ & $\begin{array}{l}\text { Creative Input } \\
\text { Need-driven } \\
\text { Bottom-up Control } \\
\text { Local traditions }\end{array}$ & $\begin{array}{l}\text { Supports trust/community } \\
\text { Allows creativity } \\
\text { Creates beauty } \\
\text { Self-determination }\end{array}$ & $\begin{array}{l}\text { Sustains trust/community } \\
\text { Connects eco-processes } \\
\text { Bottom-up control } \\
\text { Simplifies care }\end{array}$ \\
\hline Access & $\begin{array}{l}\text { Open } \\
\text { Low cost } \\
\text { Supports skill building } \\
\text { Comprehensible }\end{array}$ & $\begin{array}{l}\text { Open } \\
\text { Producer-owned } \\
\text { Supports skill building } \\
\text { Local knowledge }\end{array}$ & $\begin{array}{l}\text { Open } \\
\text { Usable by anyone } \\
\text { Local knowledge } \\
\text { Transforms constraints }\end{array}$ & $\begin{array}{l}\text { Usable by anyone } \\
\text { Low cost } \\
\text { Comprehensible } \\
\text { Transforms constraints }\end{array}$ \\
\hline Adaptability & $\begin{array}{l}\text { Everyday tools } \\
\text { Small scale } \\
\text { Everywhere possible } \\
\text { Standardized materials }\end{array}$ & $\begin{array}{l}\text { Everyday tools } \\
\text { Small scale } \\
\text { Permantently changeable } \\
\text { Modular }\end{array}$ & $\begin{array}{l}\text { Repairable by skill } \\
\text { Independent use possible } \\
\text { Permanently changeable } \\
\text { Encourages diversity }\end{array}$ & $\begin{array}{l}\text { Repairable by skill } \\
\text { Locally operable } \\
\text { Permanently changeable } \\
\text { Encourages diversity }\end{array}$ \\
\hline Bio-Interaction & $\begin{array}{l}\text { Improving soil/water } \\
\text { Supports clean air } \\
\text { Biodegradable } \\
\text { Nonviolent }\end{array}$ & $\begin{array}{l}\text { Improving soil/water } \\
\text { Supports clean air } \\
\text { Biodegradable } \\
\text { Nonviolent }\end{array}$ & $\begin{array}{l}\text { Improving soil/water } \\
\text { Supports clean air } \\
\text { Biodegradable } \\
\text { Nonviolent }\end{array}$ & $\begin{array}{l}\text { Improving soil/water } \\
\text { Supports clean air } \\
\text { Biodegradable } \\
\text { Nonviolent }\end{array}$ \\
\hline Appropriateness & $\begin{array}{l}\text { Renewable } \\
\text { Locally available } \\
\text { Re-useable } \\
\text { Durable }\end{array}$ & $\begin{array}{l}\text { Frugal material use } \\
\text { Standardized tools } \\
\text { Joyful worktime } \\
\text { Byproducts are used }\end{array}$ & $\begin{array}{l}\text { Sustains sufficiency } \\
\text { Re-used } \\
\text { Joyful time } \\
\text { Durable }\end{array}$ & $\begin{array}{l}\text { Frugal material use } \\
\text { Sustains sufficiency } \\
\text { Joyful time } \\
\text { Local settings }\end{array}$ \\
\hline
\end{tabular}

Figure 1. Dimensions and levels of the MCT. Adapted by: https://www.andrereichel.de/2019/05/ 20/artificial-intelligence-convivial-technology/. Accessed on 6 July 2021.

Contemporary tools for assessing the life cycle sustainability impact of products, such as environmental Life Cycle Assessment and Life Cycle Sustainability Assessment methods, tend to focus on a specific pillar of sustainability (i.e., environmental, social, economic). In that sense, the MCT could broaden our understanding of the complexity entailed in systems and social relations [39] by incorporating social, environmental, economic but also cultural and political elements towards comprehensive sustainability assessments.

The reconciliation of environmental, social, economic, spatial, and cultural demands in the construction process is essential for sustainable practices. Vernacular buildings exemplify how the reconciliation of natural elements and building components is possible. Such buildings are made of materials, such as stone, wood, mud, and straw that come from the nearby environment and undergo minimal processing. Natural resources (such as the soil, sun, vegetation, and wind) are used to fulfil to some extent the energy demands for cooling, heating, and lighting. Hence, harmonious interactions between the building, climate, and natural environment are fostered, following the principles of biophilic design [40]. These principles enhance energy saving, economic efficiency, environmental gains, and the improvement of indoor living conditions.

The construction of vernacular buildings is founded on intrinsically convivial construction principles, given the use of local resources to meet economic and natural limitations and the collaborative construction processes involved in relevant practices. More specifically, the region-specific nature of vernacular buildings is evident since local elements, like customs, religions, climate, and topography, are considered [41]. Despite local variations, vernacular buildings share common principles [42], including the utilisation of natural specificities (such as raw materials and energy sources) and the accrued knowledge of communities. This knowledge is empirically gained from observations of the natural environment and experimentations with local construction materials and techniques, enabling communities to build structures collaboratively and intuitively, while the need for profes- 
sionals is usually minimised $[43,44]$. In the next section, we introduce the OCSs framework as a tool that could enable a conviviality-based sustainability in building construction.

\section{Open Construction Systems as a Convivial Framework for Building Construction}

In the light of the pressing need for sustainable practices in the construction sector, we discuss how a sustainable paradigm in buildings could take place using conviviality as a core tenet. We build on existing research around the exploration of DGML solutions from a degrowth perspective with emphasis on conviviality [11,45], illuminating a DGML-based framework in building construction that incorporates vernacular architecture but also relies on contemporary technologies. To this end, we explore the conviviality dynamics of OCSs, which have been studied from multifaceted aspects, ranging from their technological dynamics $[46,47]$ to their socioinstitutional potential $[46,48]$. To narrow down the ambiguity entailed in the concept of conviviality [49], the MCT is used as a normative schema to provide insights on how OCSs could enhance conviviality in building construction.

\subsection{Conceptual Framework of Open Construction Systems}

In this subsection, we employ the conceptual framework of the DGML configuration 1 to delineate the contours of commons-based practices in building construction, albeit in a seed form $[46,48]$. We unravel the conditions under which such practices could thrive utilising the core principle of conviviality. In this vein, we aspire to prefigure alternative meaningful practices in building construction [50].

We use the term OCSs to delineate a set of connected "things" and "devices" that operate together in designing globally and manufacturing locally buildings. This set may include i. equipment (such as parametric design tools and local manufacturing technologies), ii. information resources (such information related to the digital commons and vernacular architecture), iii. community practices (such as the ones implemented in makerspaces or by open source communities), and iv. legal components (such as public copyright licences and building regulations).

Open Building Systems (OBSs) are the starting point of OCSs. The term OBSs was introduced to describe modular building components able to form a variety of building types [51,52]. OBSs are based on structured components that allow for interchangeability and present a certain degree of customisation and flexibility. The concept of OCSs expands the focus of attention from the building structure to the necessary ecosystem for fostering the lifecycle management of OBSs. Initiatives like the Hexayurt, the Open Source Ecology Microhouse, and the WikiHouse exemplify emerging forms of OCSs [46]. Figure 2 represents the conceptual framework of OCSs. 


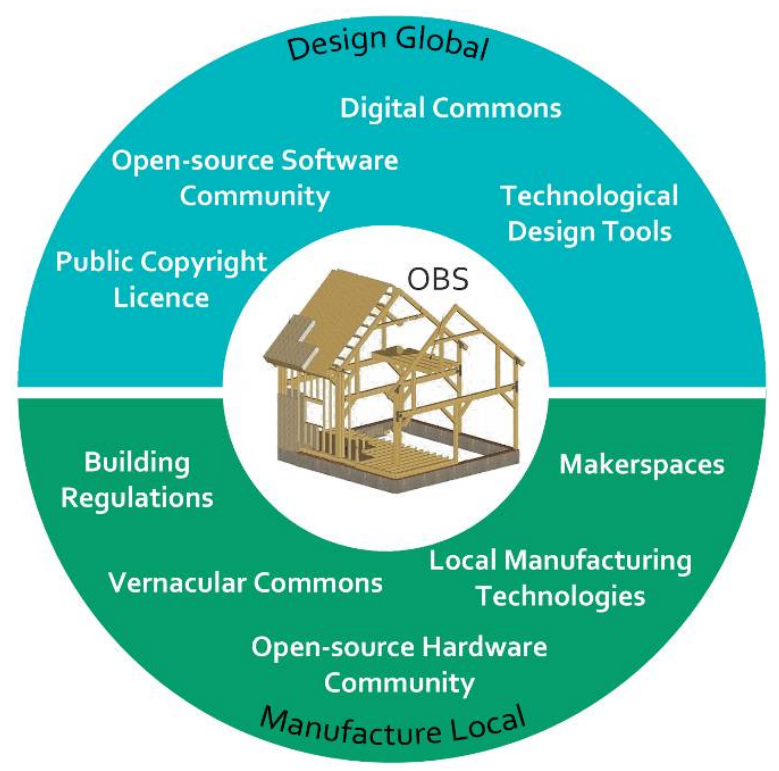

Figure 2. Conceptual framework of OCSs.

OCSs prefigure niche practices that take place on the margins of the dominant paradigm through community-based processes. They question the conventional construction model by inaugurating a new organisational and production framework that moves away from market-regulated structures. Given that issues like environmental concerns, social exclusion, and labour-intensive activities in building construction are common to all contexts, communities involved in the development of OCSs share common values and principles, which promote collaboration and bonding among the communities, and attempt to actively address the aforementioned issues.

However, beyond such shared focus of OCSs, a combination of cultural, economic, social, and techno-political specificities shapes the goals, interests, actions, and structure of OCSs locally. Each of these community-driven initiatives has its own goals, ranging from providing disaster relief shelters (like the Hexayurt initiative) to developing highperformance and affordable buildings (like the WikiHouse initiative). By providing a framework for OCSs, we want to urge engineers and social scientists to visualise common paths towards sustainable construction practices, bringing humanity and conviviality into focus [53]. Our ultimate goal is to highlight the capacity of OCSs to advance societal transformation and rouse meaningful processes of social change.

\subsection{Three Interlocked Elements for Conviviality}

In this section, we elaborate on three interrelated elements, i.e., modularity, sharing, and adaptability, observed in OCSs that seem to create positive feedback loops for conviviality, which respectively enhances sustainability. More specifically, modularity enables the decomposition and recombination of building modules, simplifying structures and increasing inclusiveness in the construction process [54] Sharing allows for the mutual benefit of individuals from the same resources and enables the production of collective value and shared purpose [55]. Adaptability is catalysed through the engagement of users in the construction process and is enabled via modularity and sharing [56].

Coming back to the five substantial features of convivial technologies that correspond to the levels of the MCT, a correlation between the five levels of the MCT and the three elements for conviviality can be made. In that sense, modularity potentially facilitates accessibility to technology (access) considering its capability to simplify complex solutions; sharing strengthens socioecological relations (relatedness, biointeraction, and appropriateness) through the promotion of bonding among the community itself and the community with the environment; adaptability facilitates the consideration of local contexts in the 
production of buildings. Figure 3 depicts the main conviviality features observed in OCSs, which are analysed below.

\subsubsection{Modularity}

Modularity refers to the property of structures to be easily decomposed and recombined in smaller parts-modules [54]. It provides a useful means to deal with complex systems and customise solutions [57,58]. Given the high complexity levels and interdependence among various stakeholders involved in building construction, modularity is important for handling the complexity of building systems. By increasing the modularity of building systems, certain processes can be structured and design decisions can be decoupled [59].

Modularity is embedded both in the design tools used but also in the structure of OBSs. During the design process of buildings, parametric design tools such as BIM technology enable the decomposability of buildings into distinct modular but interrelated components, which function independently to enhance computational analyses of buildings. Although parametric tools in principle allow for infinite modifications in the form and shape of components, fixed rules apply so that BIM software can grasp internal relationships between building components. These rules impose restrictions on the accurate design of certain elements of vernacular buildings since standardised building components are used to form structures and superstructures [60].

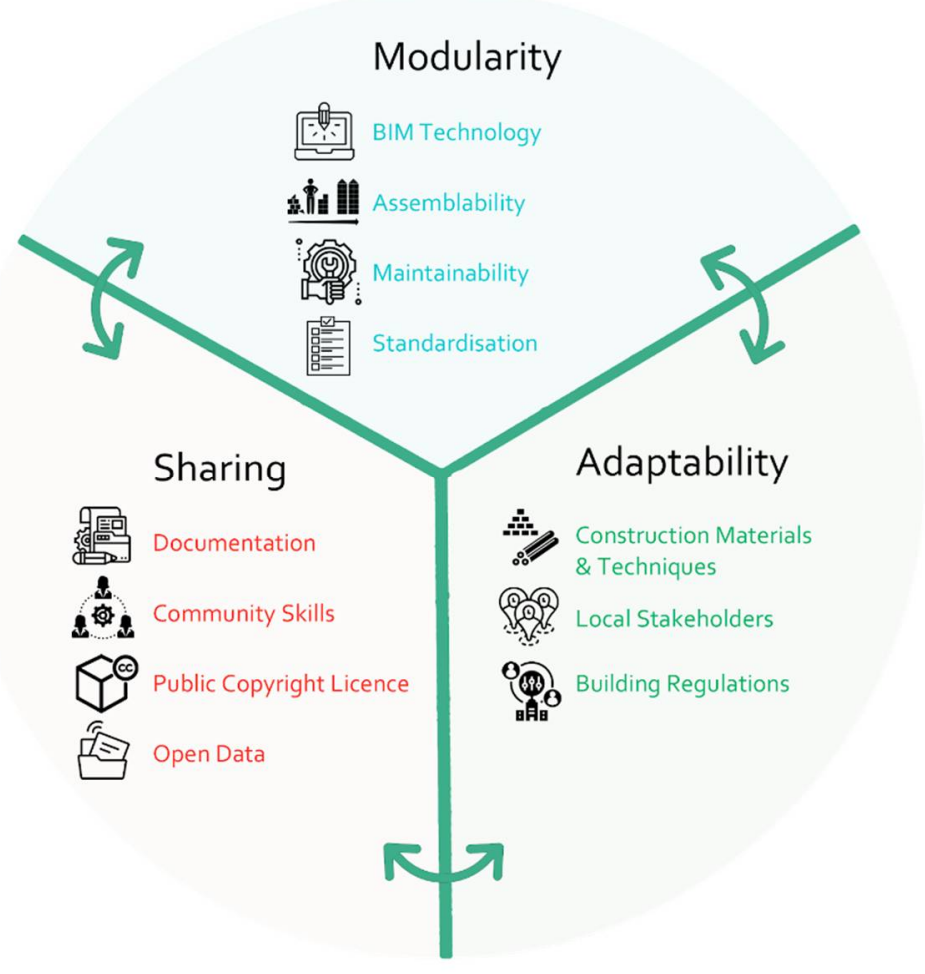

Figure 3. Conviviality features of OCSs.

Thus, the structuring of building information enabled through BIM technology creates both a challenge and an opportunity. The challenge is related to the need for explicitly defined rules that may obstruct the imprint of distinctive building components [47]. The opportunity correlates with the capability to replicate building solutions by codifying and sharing parameterised objects. Such a potential empowers BIM technology to provide a precise interface with an integrated set of applications for well-defined modular building types, like the WikiHouse.

The design-embedded modularity in OBSs facilitates the construction, maintenance, and disposal of OBSs. For example, a WikiHouse structure includes the structural frame- 
work (chassis), the electrical equipment, the foundation, the mechanical equipment, the roof, and solar utilities. With the aid of modularity, all these subsystems can be constructed asynchronously and the surrounding community can participate depending on ability and interests to undertake specific parts of the construction process. Additionally, certain tasks can be outsourced to expedite but also simplify the entire process [54]. Modularity hence leads to a division of human labour that reduces the overall complexity of the construction process and makes the entire process more accessible and inclusive. It offers the flexibility to independently piece together, modify, rearrange, repair, and substitute modules so that the needs of users are best suited. Thus, modularity strengthens social interactions and community building, which are crucial for a more sustainable future.

\subsubsection{Sharing}

Sharing and collaboration are fundamental for all stages of the construction process of OCSs. Sharing takes place both in distributed makerspaces, where equipment and simple tools are used by local communities, but also online, given that digital resources are utilised for the production of open source building solutions. Collaborative processes are evident throughout the construction stage of OCSs, where subgroups work asynchronously on the assembly process of different parts, developing friendship and joyful feelings [48]. Shared resources are managed by communities, which set the rules for using resources in a fairer manner for all, with an eye to optimising production while minimising the processing of material. Recyclable, locally sourced, and reused materials are preferred to mitigate environmental impacts.

The existence of detailed documentation guides/manuals facilitates the replicability and openness of OCSs [61]. Architectural data, construction details, as well as chemical, environmental, economic, and biophysical information should be extensively documented to foster autonomy during the construction and maintenance phases of OBSs. Additionally, by accessing international codified datasets of vernacular architecture and disseminating construction practices of various districts, experimentation and combinations of best practices could be fostered, spreading the impact of local commons-based initiatives. Nevertheless, in the current stage of OCSs, fragmentation issues arise due to the lack of a comprehensive platform that includes all the up-to-date information around them. For instance, in the case of the WikiHouse, uncategorised and non-engineered design files are usually shared on online platforms, like GitHub. Besides, the existence of a complete bill of materials for OCSs is challenging considering the context-dependent nature of buildings [48].

Additionally, the plurality of expertise and skills among the participants in the construction process enhances autotomy during the construction and maintenance stages of OBSs. The level of conviviality in the construction phase rises when a highly engaged community with a strong supporting network is involved. However, in the current stage of OCSs, concerns have been raised regarding the ability of users to maintain certain building infrastructures, such as plumbing and electricity modules [48]. Technical interventions are hence necessary at certain stages which indicates that OCSs still have a long way to go.

Concerning the legal framework required, Creative Commons public copyright licences enable the free distribution of building solutions facilitating the integration of the construction industry. Such a condition empowers broad participation in the research and development of OCSs by providing technical support to local communities throughout the building supply chain.

Raising awareness about the importance of scaling up the impact of OCSs for humanity is significant to foster conviviality through the engagement of individuals in relevant processes. Some steps to this direction could be made through the orientation of science and education towards open data, the promotion of open source technologies by policymakers, and the integration of open source structured protocols for data sharing and coordination among stakeholders: from local governments and professionals to international organisations. Such protocols could set the ground for the effective implementation of construction practices in each region and country and the establishment of networks 
and partnerships at regional, national, and international levels. Moreover, the physical infrastructure needed for the development of OCSs should be provided, including the creation of physical co-working spaces and distributed ad hoc divisions for consultancy on administrative procedures at a national level.

\subsubsection{Adaptability}

The international homogenisation of building structures taking place through unsustainable construction practices has indicated the need for adaptability to local contexts with an eye to biophysical conditions [62]. The emphasis of OCSs is placed on endorsing adaptability according to human needs rather than offering one-size-fits-all solutions. Following, we elaborate on the ways adaptability could enhance conviviality and help form a more sustainable construction sector.

During the introduction of OBSs, monolithic and standardised materials are usually used as a starting point to facilitate experimentations with OBSs. For instance, standardised sheets of plywood are used for the construction of the WikiHouse chassis system usually obtained from Finnish wood industry producers. As the pool of digital commons for OCSs grows, new materials and designs are being tested in local contexts to enhance the performance of buildings through the use of sustainable materials and techniques. The use of open data could democratise accessibility to material-related properties and performance data. In this direction, platforms, like Materiom (https://materiom.org/. Accessed on 6 July 2021), can provide recipes for materials made from natural and biobased ingredients, including agricultural waste. In that sense, open source databases could further decentralise the production of OCSs by providing the means needed to self-produce construction materials.

Distributed networks of local stakeholders (architects, manufacturers, designers, structural engineers) could provide technical support to end users and modify digital resources based on regional specificities. OBSs bear an inherent potential for adaptability to local building regulations owing to their design-embedded modularity that enables modification of building components to fit predefined geometric constraints. The development of open databases with regulation-related documents and the simplification of international technical guidelines could enhance the reproducibility of OCSs at local levels [63]. Finally, using smart features and geospatial technologies, certain types of OBSs, building regulations, available construction materials, and administrative processes could be pointed to on a context-specific basis.

\section{Conclusions}

Despite the plurality of existing perspectives towards sustainable construction, the challenge still remains unanswered. To provide preliminary answers to sustainable practices in building construction, we explore an alternative production model, the DGML configuration that brings the social elements of sharing and solidarity into focus. We stress the importance of introducing conviviality elements in building construction, which could foster a meaningful sustainability paradigm. In this regard, we delineate the contours of DGML in building construction through the concept of OCSs, illustrating the positive dynamics for conviviality. Hence, we identify three interlocked elements for conviviality in OCSs: design-embedded modularity, sharing practices of digital and physical infrastructures, and adaptability to local contexts.

Though our analysis, we conclude that OCSs present non-negligible tendencies towards a conviviality-based sustainability. We also formulate proposals to boost the conviviality potential of OCSs, such as advancements in Building Information Modelling technology; the implementation of open source protocols for data sharing; the institutionalisation of open source communities; as well as the integration of existing open source platforms to facilitate accessibility to building information.

Considering the involvement of diverse stakeholders, including professionals and governmental organisations (i.e., central government, local authorities, etc.) in the construction 
processes, the above-mentioned issues cannot be addressed in the absence of cooperation across stakeholders and institutional transformations. By stimulating policy-making efforts to build relevant institutions, OCSs could pave the way for an inclusive and democratic approach in the construction sector. To enable the flourishing of OCSs at regional, national, and global levels, awareness should be raised about the socioenvironmental considerations in the construction sector.

A point of criticism one may level against this article is the lack of empirical data regarding the maintenance and disposal stages of OCSs, which is due to the seed form of OCSs. We invite future research to focus on evidence-based assessments for these stages to provide sound data about the lifecycle performance of OCSs. A comprehensive sustainability comparison of an industrially produced building with a similar OBS would also be beneficial. For that purpose, a compilation of targeted and structured tools should be used to assess both the building structure and the ecosystem around it. The development and institutionalisation of such tools could foster meaningful sustainability assessments in building construction, facilitating the investigation of OCSs developed in different socioeconomic contexts.

Lessons should be drawn from global experiences and effective strategies should be developed on local levels, bearing in mind regional social, economic, and political specificities. Vernacular architecture can be a useful asset for defining principles for sustainable design at local contexts, while offering the opportunity to digest and assimilate conviviality values. Such values could enable us to build a common future with a particular focus on human interrelation and wellbeing. In that sense, we do not expect self-construction usually observed in vernacular practices to become a dominant construction practice. Our proposition is that certain elements of vernacular architecture, within the DGML configuration, could be utilised to point the way towards a more sustainable building sector. We thus believe that OCSs could introduce a promising pathway for fostering convivial practices in building construction by reinvigorating vernacular buildings. This could potentially mobilise individuals to acquire a more active role in building construction. The question, however, of whether we want to follow a promising but arduous path towards a sustainable future remains; and the answer is up to us.

Author Contributions: Conceptualization, C.P., V.K. and V.N.; writing-original draft preparation, C.P. and V.N.; writing-review and editing, C.P. and N.T.; visualization, N.T. and C.P.; supervision, V.N. and V.K.; project administration, N.T. and C.P.; funding acquisition, V.K. and N.T. All authors have read and agreed to the published version of the manuscript.

Funding: Vasilis Kostakis and Christina Priavolou acknowledge funding from the European Research Council (ERC) under the European Union's Horizon 2020 research and innovation programme (grant No. 802512). This work has been supported by the European Commission through the H2020 project Finest Twins (grant No. 856602).

Acknowledgments: We are grateful to Chris Giotitsas who provided guidance to the document.

Conflicts of Interest: The authors declare no conflict of interest. 


\section{Appendix A}

The Matrix of Convivial Technology by Vetter (2018).

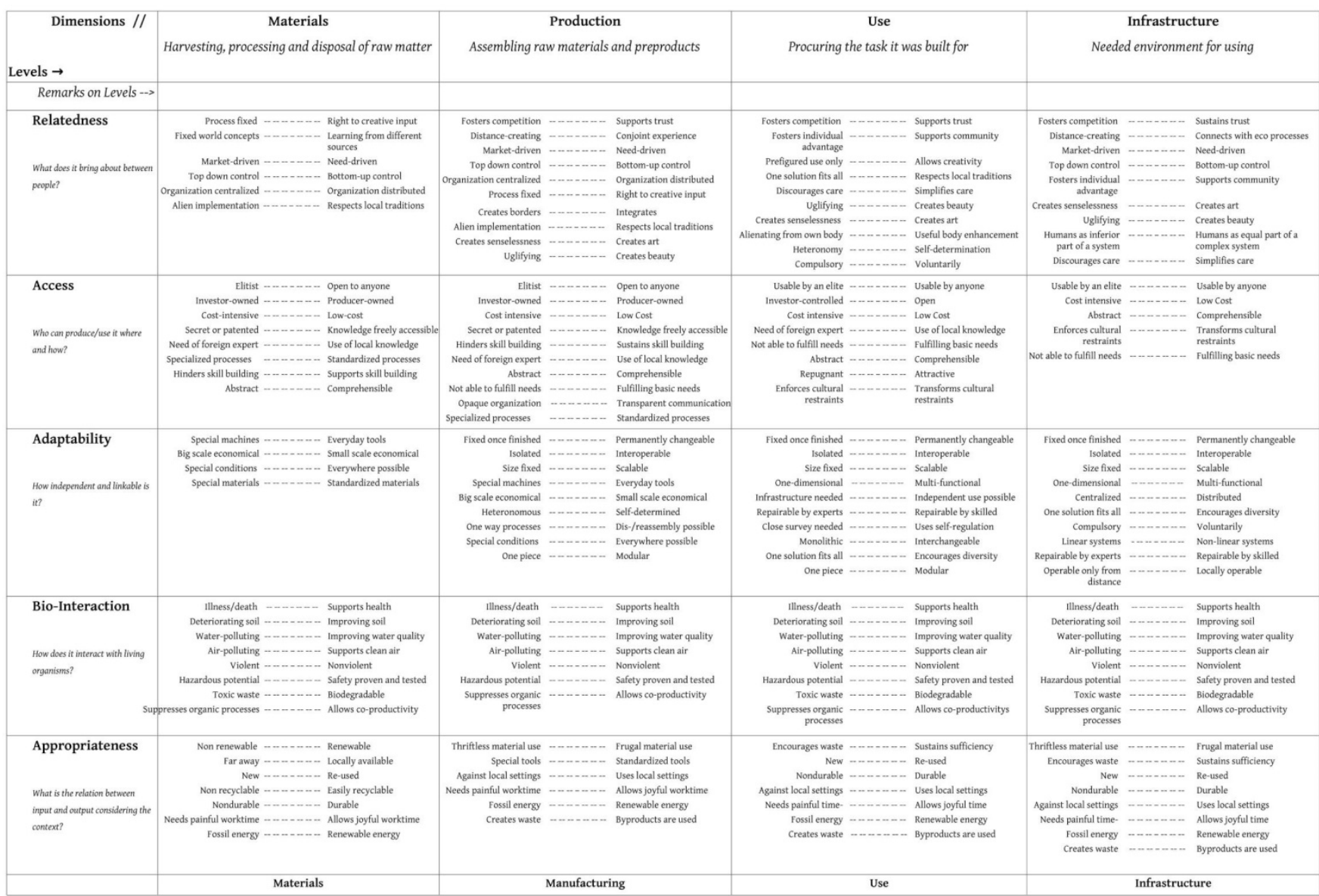

\section{References}

1. Kuhlman, T.; Farrington, J. What is Sustainability? Sustainability 2010, 2, 3436-3448. [CrossRef]

2. Morelli, J. Environmental Sustainability: A Definition for Environmental Professionals. J. Environ. Sustain. 2011, 1, 2. [CrossRef]

3. Purvis, B.; Mao, Y.; Robinson, D. Three pillars of sustainability: In search of conceptual origins. Sustain. Sci. 2019, 14, 681-695. [CrossRef]

4. Akadiri, P.; Chinyio, E.; Olomolaiye, P. Design of A Sustainable Building: A Conceptual Framework for Implementing Sustainability in the Building Sector. Buildings 2012, 2, 126-152. [CrossRef]

5. Solaimani, S.; Sedighi, M. Toward a holistic view on Lean sustainable construction: A literature review. J. Clean. Prod. 2019, 248, 119213. [CrossRef]

6. Illich, I. Tools for Conviviality; Fontana/Collins: Sydney, Australia, 1973.

7. Büchs, M.; Koch, M. Challenges for the degrowth transition: The debate about wellbeing. Futures 2019, 105, 155-165. [CrossRef]

8. Luhmann, N. The future cannot begin: Temporal structures in modern society. Soc. Res. 1976, 43, 130-152.

9. Hirsch, F. Social Limits to Growth; Harvard University Press: Cambridge, MA, USA, 1976.

10. Offer, A. The Challenge of Affluence: Self-Control and Wellbeing in the United States and Britain Since 1950; Oxford University Press: Oxford, UK, 2006.

11. Kostakis, V.; Liarokapis, M.; Latoufis, K.; Bauwens, M. The convergence of digital commons with local manufacturing from a degrowth perspective: Two illustrative cases. J. Clean. Prod. 2016, 197, 1684-1693. [CrossRef]

12. Borowy, I.; Aillon, J.L. Sustainable health and degrowth: Health, health care and society beyond the growth paradigm. Soc. Theory Health 2017, 15, 346-368. [CrossRef]

13. Vetter, A. The matrix of convivial technology: Assessing technologies for degrowth. J. Clean. Prod. 2018, 197, 1778-1786. [CrossRef]

14. Larson, K.; Intille, S.; McLeish, T.; Beaudin, J.; Williams, R. Open source building: Reinventing places of living. Build. Technol. J. 2004, 22, 87-200. [CrossRef]

15. Parvin, A. Architecture (and the other 99\%): Open-source architecture and design commons. Archit. Des. 2013, 83, 90-95. [CrossRef]

16. Du Plessis, C. An Agenda 21 for sustainable construction in developing countries. Sustain. Build. 2002, 27, 379-390. 
17. Abergel, T.; Dean, B.; Dulac, J. Towards a Zero-Emission, Efficient, and Resilient Buildings and Construction Sector: Global Status Report 2017; UN Environment and International Energy Agency: Paris, France, 2017.

18. Rode, P.; Burdett, R.; Soares-Gonçalves, J.C. Buildings: Investing in energy and resource efficiency. In The United Nations Environment Programme, towards a Green Economy: Pathways to Sustainable Development and Poverty Eradication; United Nations Environment Programme: Nairobi, Kenya, 2011; pp. 331-373.

19. Eastman, C.; Teicholz, P.; Sacks, R.; Liston, K. BIM Handbook: A Guide to Building Information Modeling for Owners, Managers, Designers, Engineers, and Contractors, 2nd ed.; John Wiley and Sons, Inc.: Hoboken, NJ, USA, 2011.

20. Marshall, D.; Worthing, D. The Construction of Houses, 3rd ed.; Estates Gazette: London, UK, 2006.

21. McKinsey Global Institute. Reinventing Construction: A Route to Higher Productivity; McKinsey \& Company: Brussels, Belgium, 2017.

22. Wong, K.; Fan, Q. Building Information Modelling (BIM) for sustainable building design. Facilities 2013, 31, 138-157. [CrossRef]

23. Benkler, Y. The Wealth of Networks: How Social Production Transforms Markets and Freedom; Yale University Press: London, UK, 2006.

24. Von Hippel, E. Democratizing Innovation; MIT Press: Cambridge, MA, USA, 2005.

25. Hess, C.; Ostrom, E. Understanding Knowledge as a Commons: From Theory to Practice; MIT Press: Cambridge, MA, USA, 2007.

26. Perez, I.; Santos, A. Distributed economies through open design and digital manufacturing. MIX Sustentável 2017, 3, 21-28. [CrossRef]

27. Matschoss, K.; Repo, P. Forward-looking network analysis of ongoing sustainability transitions. Technol. Forecast. Soc. Chang. 2020, 161, 120288. [CrossRef]

28. Kohtala, C. Addressing sustainability in research on distributed production: An integrated literature review. J. Clean. Prod. 2015, 106, 654-668. [CrossRef]

29. Benkler, Y.; Shaw, A.; Hill, B.M. Peer production: A form of collective intelligence. In Handbook of Collective Intelligence; Malone, T., Bernstein, M., Eds.; MIT Press: Cambridge, MA, USA, 2015.

30. Guiltinan, J. Creative destruction and destructive creations: Environmental ethics and planned obsolescence. J. Bus. Ethics 2009, 89, 19-28. [CrossRef]

31. Krüger, O. The paradox of sustainable degrowth and a convivial alternative. Environ. Values 2019, 28, 233-251. [CrossRef]

32. Dempsey, N.; Bramley, G.; Power, S.; Brown, C. The social dimension of sustainable development: Defining urban social sustainability. Sustain. Dev. 2011, 19, 289-300. [CrossRef]

33. Kallis, G. In defence of degrowth. Ecol. Econ. 2011, 70, 873-880. [CrossRef]

34. Meng, Y.; Yang, Y.; Chung, H.; Lee, P.-H.; Shao, C. Enhancing sustainability and energy efficiency in smart factories: A review. Sustainability 2018, 10, 4779. [CrossRef]

35. Dahmus, J.B.; Gutowski, T.G. Can efficiency improvements reduce resource consumption? A historical analysis of ten activities. J. Ind. Ecol. 2011, 18, 883-897. [CrossRef]

36. Deriu, M. Conviviality. In Degrowth: A Vocabulary for a New Era; D’Alisa, G., Demaria, F., Kallis, G., Eds.; Routledge: London, UK, 2015; pp. 79-82.

37. Muraca, B.; Neuber, F. Viable and convivial technologies: Considerations on climate engineering from a degrowth perspective. J. Clean. Prod. 2017, 197, 1810-1822. [CrossRef]

38. Lizarralde, I.; Tyl, B. A framework for the integration of the conviviality concept in the design process. J. Clean. Prod. 2017, 197, 1766-1777. [CrossRef]

39. Rzepnikowska, A. Migrant experiences of conviviality in the context of Brexit: Polish migrant women in Manchester. Cent. East. Eur. Migr. Rev. 2020, 9, 65-83.

40. Gillis, K.; Gatersleben, B. A Review of Psychological Literature on the Health and Wellbeing Benefits of Biophilic Design. Buildings 2015, 5, 948-963. [CrossRef]

41. Salman, M. Sustainability and vernacular architecture: Rethinking what identity is. In Urban and Architectural Heritage Conservation within Sustainability; Hmood, K., Ed.; Intechopen: Rijeka, Croatia, 2018.

42. Walid, A.; Omar, F. Vernacular architecture approach to achieve sustainability in informal settlements. Proc. Word SB 2014, 14, 200-207.

43. Gruen, J.P. Vernacular architecture. In Encyclopedia of Local History; Wilson, A.H., Ed.; Rowman \& Littlefield: Lanham, MD, USA, 2017; pp. 697-698.

44. Oliver, P. Encyclopedia of Vernacular Architecture in the World; Cambridge University Press: Cambridge, UK, 1997.

45. Parrique, T. The Political Economy of Degrowth; Economics and Finance, Université Clermont Auvergne; Stockholms Universitet: Stockholm, Sweden, 2019.

46. Priavolou, C. The emergence of open construction systems: A sustainable paradigm in the construction sector? J. Futures Stud. 2018, 23, 67-84.

47. Priavolou, C. To BIM or not to BIM? Lessons learned from a Greek vernacular museum building. AIMS Environ. Sci. 2020, 7 , 192-207. [CrossRef]

48. Priavolou, C.; Niaros, V. Assessing the openness and conviviality of open source technology: The case of the WikiHouse. Sustainability 2019, 11, 4746. [CrossRef]

49. Caire, P. How to import the concept of conviviality to web communities. Int. J. Web Based Commun. 2010, 6, 99-113. [CrossRef] 
50. Wittmayer, J.M.; Backhaus, J.; Avelino, F.; Pel, B.; Strasser, T.; Zuijderwijk, L. Narratives of change: How social innovation initiatives construct societal transformation. Futures 2019, 112, 102433. [CrossRef]

51. Kamar, K.A.M.; Ismail, E.; Hamid, Z.A.; MohdZin, M.Z.; Ghani, M.K.; Rahim, A.H. Understanding Open Systems in IBS; B \& I Magazine: Selangor, Malaysia, 2010.

52. Siw, W.Y. Open Building System towards Functional Sustainability for Affordable Housing in Malaysia; Universiti Teknologi Malaysia: Johor Bharu, Malaysia, 2013.

53. Adloff, F. Convivialist Manifesto: A Declaration of Interdependence; Käte Hamburger Kolleg/Centre for Global Cooperation Research: Duisburg, Germany, 2014.

54. Kostakis, V. How to reap the benefits of the digital revolution? Modularity and the commons. Halduskultuur 2019, $20,4-19$.

55. Bollier, D.; Helfrich, S. Free, Fair and Alive. The Insurgent Power of the Commons; New Society Publishers: Philadelphia, PA, USA, 2019.

56. Elgammal, A.; Papazoglou, M.; Krämer, B.; Constantinescu, C. Design for customization: A new paradigm for product-service system development. Procedia CIRP 2017, 64, 345-350. [CrossRef]

57. Baldwin, C.Y.; Clark, K.B. Design Rules: The Power of Modularity; MIT Press: Cambridge, MA, USA, 2002.

58. Gershenson, J.K.; Prasad, G.J.; Zhang, Y. Product modularity: Definitions and benefits. J. Eng. Des. 2003, 14, 295-313. [CrossRef]

59. Viana, D.D.; Tommelein, I.D.; Formoso, C.T. Using modularity to reduce complexity of industrialized building systems for mass customization. Energies 2017, 10, 1622. [CrossRef]

60. Open Structures. Can We Design Hardware Like How We Design Software? Open Structures. 2021. Available online: https: / / openstructures.net/ (accessed on 6 July 2021).

61. Bonvoisin, J. Implications of Open Source Design for Sustainability. In Sustainable Design and Manufacturing; Setchi, R., Howlett, R.J., Liu, Y., Theobald, P., Eds.; Springer: Berlin/Heidelberg, Germany, 2016; pp. 49-59.

62. Guggenheim, M.; Söderström, O. Re-Shaping Cities: How Global Mobility Transforms Architecture and Urban Form; Routledge: London, UK, 2010.

63. Open Building Institute. What We Do. Open Building Institute. 2020. Available online: https://www.openbuildinginstitute.org/ about-what-we-do/ (accessed on 6 July 2021). 